\title{
Dura-arachnoid lesions produced by 22 gauge Quincke spinal needles during a lumbar puncture
}

\author{
M A Reina, A López, V Badorrey, J A De Andrés, S Martín
}

J Neurol Neurosurg Psychiatry 2004;75:893-897. doi: 10.1136/jnnp.2003.017624

See end of article for authors' affiliations ......................

Correspondence to: Dr M A Reina, Valmojado $951^{\circ} \mathrm{B}, 28047$ Madrid Spain; miguelangel.rei@ terra.es

Received 27 April 2003 Revised

22 September 2003

Accepted in final revised form 14 October 2003
Aims: The dural and arachnoid hole caused by lumbar puncture needles is a determining factor in triggering headaches. The aim of this study is to assess the dimensions and morphological features of the dura mater and arachnoids when they are punctured by a 22 gauge Quincke needle having its bevel either in the parallel or in the transverse position.

Methods: Fifty punctures were made with 22 gauge Quincke needles in the dural sac of four fresh cadavers using an "in vitro" model especially designed for this purpose. The punctures were performed by needles with bevels parallel or perpendicular to the spinal axis and studied under scanning electron microscopy.

Results: Thirty five of the 50 punctures done by Quincke needles (19 in the external surface and 16 in the internal) were used for evaluation. When the needle was inserted with its bevel parallel to the axis of the dural sac (17 of 35), the size of the dura-arachnoid lesion was $0.032 \mathrm{~mm}^{2}$ in the epidural surface and $0.037 \mathrm{~mm}^{2}$ in the subarachnoid surface of the dural sac. When the needle's bevel was perpendicular to the axis ( 18 of 35 ) the measurement of the lesion size was $0.042 \mathrm{~mm}^{2}$ for the external surface and 0.033 $\mathrm{mm}^{2}$ for the internal. There were no statistical significant differences between these results.

Conclusions: It is believed that the reported lower frequency of postdural puncture headache when the needle is inserted parallel to the cord axis should be explained by some other factors besides the size of the dura-arachnoid injury.
B ier and his assistant Hidelbrant ${ }^{1}$ reported the first postdural puncture headache (PDPH) in 1898 when they injected subarachnoid cocaine to each other, developing intense headaches afterwards. Mac Robert ${ }^{2}$ postulated in 1918 that cerebrospinal fluid (CSF) leakage after a lumbar puncture plays a decisive part in triggering the headache. More than a 100 years later and the problem continues. In the year 2000, a subcommittee of the American Academy of Neurology provided recommendations to reduce the occurrence of PDPH. ${ }^{3}$

It has been widely accepted that CSF, leaking from the subarachnoid space into the epidural space through a dura puncture hole, causes a low CSF pressure leading to cerebral vasodilatation allowing the brain and its supporting structure to sag. Both mechanisms have been postulated as the main triggers of the headache..$^{4-6}$

There are different factors linked to the appearance of PDPH. Some such as age, sex, pregnancy, and previous PDPH history, cannot be changed. However, the size of the dural hole can be influenced and is closely related to the frequency and severity of PDPH. ${ }^{4-6}$ It is accepted that the smaller the size of the dural lesion the lower the percentage of headaches, therefore the recommendation to use thin, nontraumatic tip needle or Quincke needles. The lateral lumbar puncture approach and the fewest possible attempts are all factors that seem to reduce the chance of PDPH. Duraarachnoid lesions (DAL) have never been observed by microscopy in a clinical setting.

When cutting needles (Quincke needles) are used the percentage of PDPH is reportedly lower when the bevel is inserted parallel to the cord axis. ${ }^{78}$ It is assumed that because of the parallel distribution of the fibres and their longitudinal orientation during the performance of a lumbar puncture the dural fibres are separated but not cut.'

Reports from the past decade have shown the complex configuration of the dural sac. ${ }^{10}$ The dura mater is a laminated structure with its thickness built up from well defined 80 concentrical layers around the spinal cord in which the fibres are oriented in different directions in the innermost layers. ${ }^{11}{ }^{12}$

The aim of this study is to evaluate the morphological features and the size of the DAL caused by a 22 gauge Quincke needle along the dural and arachnoid components of the dural sac and the role of the needle position when inserted parallel or transversely to the axis of the spinal cord.

\section{METHODS}

This study has been conducted after local ethics committee approval. Relatives of four patients were approached and asked for permission to remove the dural sac and its neural content immediately after death. Age of the patients ranged between 46 and 60 years. Patients had been admitted to the neurointensive care unit with cerebral haemorrhage and diagnosed subsequently of brain stem death. Mechanical ventilation and haemodynamic support were maintained throughout until organ extraction. Through an anterior approach vertebrectomy, the dural sac from the eighth thoracic vertebra to the fifth lumbar vertebra was removed.

\section{In vitro procedures}

The spinal cord and the dural sac were dissected and the nerve roots crossing the dural sac were removed to leave the dural sac isolated by the dura mater and the arachnoids. The approximate time from the complete extraction of organs (cessation of blood flow and oxygenation) up to the extraction of dural sac samples was one hour. To maintain its cylindrical structure, to avoid irregularities of the membranes and the effect of radial forces, the dural sac

Abbreviations: PDPH, postdural puncture headache; CSF, cerebrospinal fluid; DAL, dura-arachnoid lesion; SEM, scanning electron microscopy 
was mounted on three aluminium rods covered with latex (fig 1). The dura mater was kept in a physiological environment by continuously spraying a saline solution to avoid any biological changes. Under these conditions, we did not find any histological changes in the samples. A 22 gauge Quincke needle (Yale Spinal Becton Dickinson needle made in Spain) was used to perform the punctures. Twenty five of fifty punctures were done in a parallel approach to the axis and the other 25 in a perpendicular one. Fifteen minutes after the punctures small dural sac samples were cut for examination and immersed for four hours in $2.5 \%$ glutaraldehyde with phosphate solution buffered to a $\mathrm{pH}$ of 7.287.32. They were then progressively dehydrated by immersion in solutions containing an ever increasing concentration of acetone (up to $100 \%$ ). The acetone from the samples was exchanged with carbon dioxide in a pressurised chamber (Balzers CPD 030 Critical Point Dryer, Bal Tec AG, Fürstentum, Liechtenstein) until a critical pressure (73.8 bar) and temperature $\left(31{ }^{\circ} \mathrm{C}\right)$ were reached. A carbon layer was then put on the samples to obtain a thickness of less that 200 Armstrong with a Balzers MED 010 Mini Deposition System (Balzers, Bal Tec AG, Fürstentum, Liechtenstein). The carbon evaporation was done by passing an electrical current through a graphite electrode within a $10^{-5}$ mill bars vacuum chamber. The samples were then covered with a golden microfilm by passing a 20 amp electrical current through a gold electrode within a vaporisation chamber SCD 004 Balzers Sputter Coater (Balzers, Bal Tec AG, Fürstentum, Liechtenstein) regulated with a vacuum pressure of 0.1 mill bars. The samples were studied in both the outer epidural surface and the inner subarachnoid surface with a JEOL JSM 6400 Scanning Electron Microscope (JEOL Corporation, Tokyo, Japan). The area of lesion of the DAL was calculated according to the photographic pictures taken once they had been amplified up to 600 times. Each lesion was an irregularly shaped geometrical figure. Its area was calculated by dividing the irregular picture into multiple triangles (3035 ) and adding them up to get the final area. The total measured error on the surface of each lesion was $2 \%$. The thickness of the dura-arachnoid membrane was measured by using a Mitutoyo micrometer 102-101 N, 0-25 mm, Mitutoyo Corporation, Japan. Six measurements were performed in each of the corpses.

The needle used in all the procedures was the 22 gauge bevelled cutting Quincke needle, as neurologists do not usually use thinner needles when performing a diagnostic lumbar puncture. The data are normally distributed. Values are expressed as means and 95\% confidence intervals. Student's $t$ test was used for statistical analysis and a p value of less than 0.05 was considered significant.

\section{RESULTS}

Of 50 punctures done by Quincke needles 35 (19 in the external surface and 16 in the internal surface) were analysed. The remaining 15 were not included because of the lack of quality of the histological preparation. Seventeen punctures were performed with the needle inserted in a parallel direction to the cord axis and 18 in a perpendicular direction. The area of the DAL when the needle bevel was in a parallel direction was $0.032 \mathrm{~mm}^{2}$ (95\%CI 0.020 to 0.044 ) on the external surface of the dural sac (epidural) (fig 2A) and $0.037 \mathrm{~mm}^{2}$ (95\%CI 0.030 to 0.044 ) on the internal surface (subarachnoid) (fig 2B). The area when the bevel was perpendicular to the axis was $0.042 \mathrm{~mm}^{2}$ (95\%CI 0.026 to 0.058 ) for the external surface (fig $3 \mathrm{~A}$ ) and $0.033 \mathrm{~mm}^{2}$ (95\%CI 0.026 to 0.040 ) for the internal (fig 3B). We found no statistically significant difference between the areas.

The average thickness of the dura-arachnoid membrane was $0.36 \mathrm{~mm}$ (95\%CI 0.30 to 0.42 ). The morphology of the

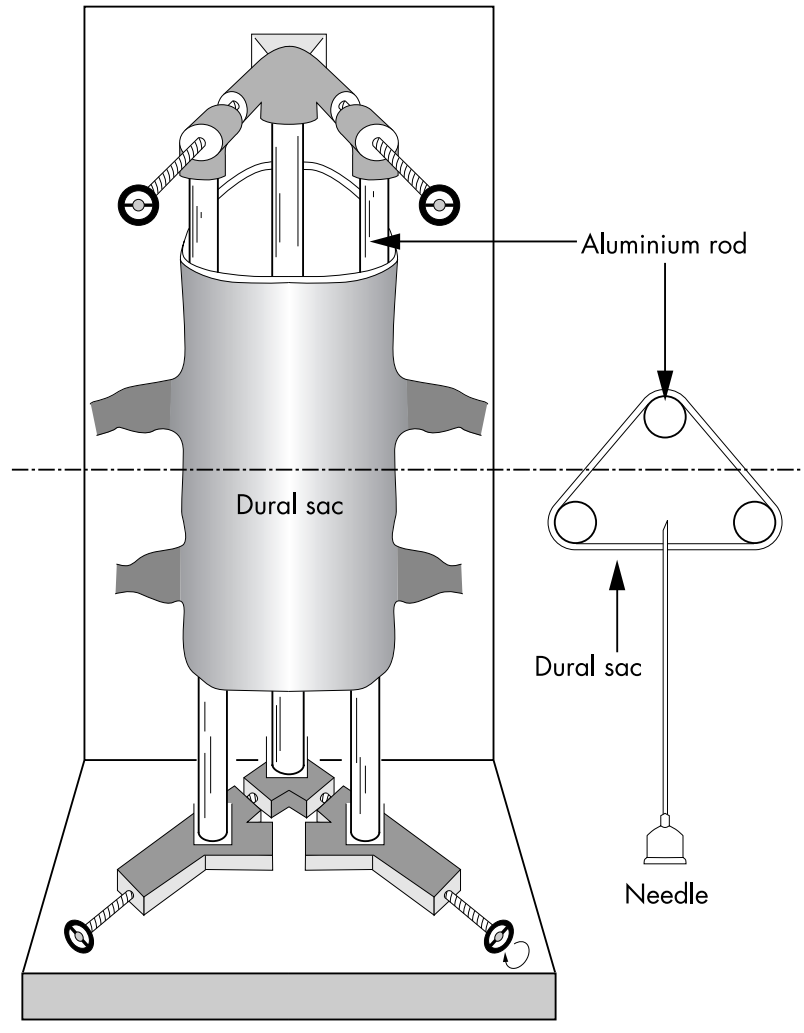

Figure 1 The "in vitro" model diagram.

DAL caused by Quincke needles had either a " $U$ " shape (figs 2 and 3) or a semi-lunar shape (fig 4A). The lesion generates a flap of dural membrane with a clean cut edge that resembles the lid of a partially opened tin. The needle orientation had no influence on the morphology of the lesion (fig 4A). When the internal surface of the dural sac was studied, we found in some of the samples elastic fibres and broken neurothelial cells around the edge of the DAL (fig 4B). In the partially closed lesions, (like a semiopen tin) we could identify dural laminas inside the thickness of the dural sac. These laminas were almost 5 microns thick.

\section{DISCUSSION}

This study has allowed us to confirm the shape and size of the DAL 15 minutes after withdrawing the spinal needle. It is accepted wisdom that the size of the dural puncture and PDPH are directly related. Therefore, the bigger the dural puncture the greater the chance of PDPH. We have shown the morphology of the DAL with a non-damaged needle pointing at different angles. When an "in vitro" puncture is performed, the tip of the needle makes a straight contact with the dural sac. In clinical practice, the needle gets through the skin and spinal ligaments before it reaches the epidural space. It can often hit rigid structures such as the vertebral laminas and the spinous processes causing damage to the needle's bevel. ${ }^{13-15}$ Our results showed no statistical differences in the size of the DAL when the needle's bevel was pointed in directions, parallel and perpendicular to the axis.

This conclusion is not supported by Franksson et al, ${ }^{9}$ who using an "in vitro model" and the help of a light microscope, stated that fewer fibres were damaged when the needle's bevel was inserted in a longitudinal way than when it was done transversely. This seminal study established the accepted clinical guidelines: to point the bevel in a parallel 

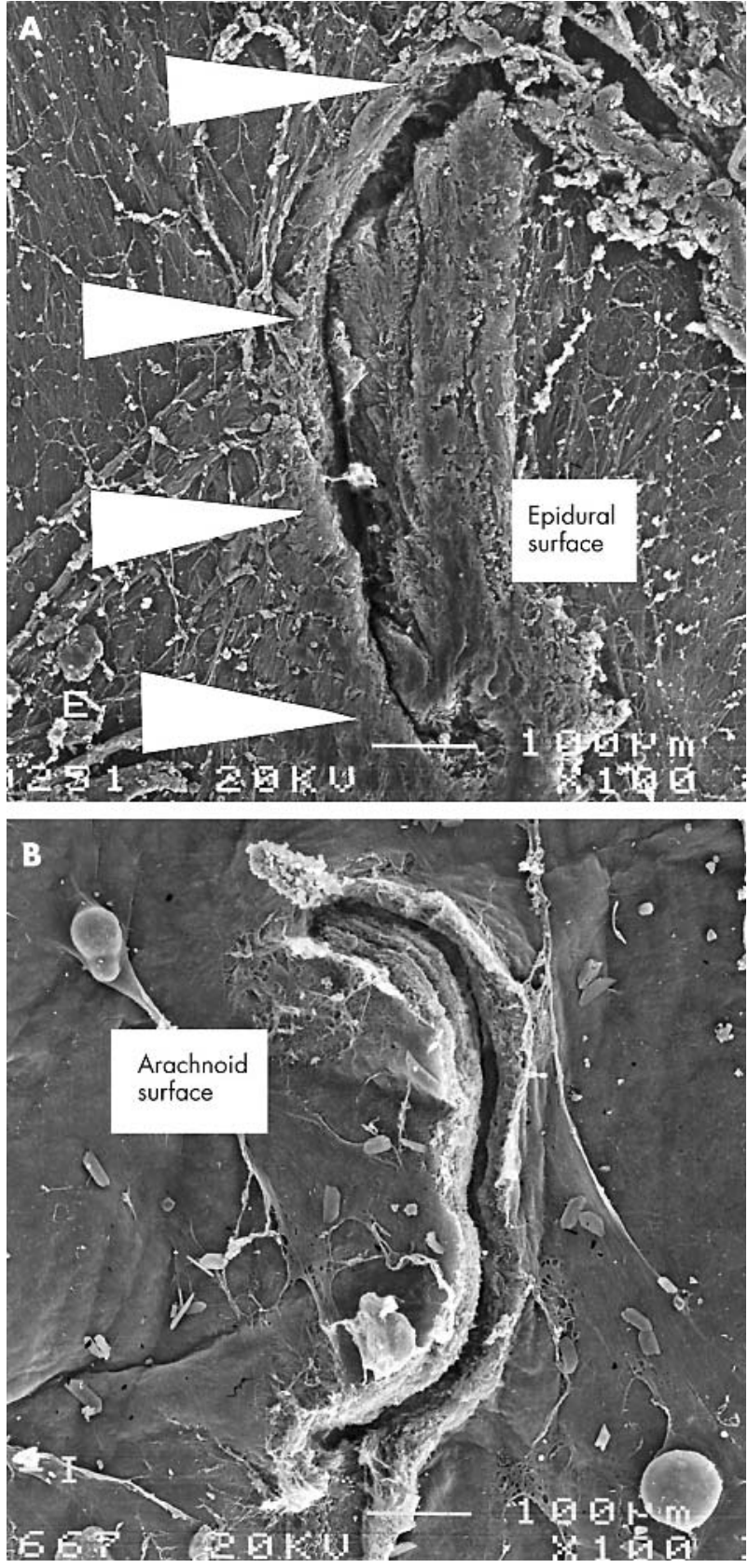

Figure 2 Dura-arachnoid lesion caused by a 22 gauge Quincke needle introduced with the bevel parallel to the axis of the spinal cord. (A) Epidural surface of the dural sac. Scanning electron microscopy $\times 100$. Bar: 100 microns. (B) Arachnoid surface of the dural sac. Scanning electron microscopy $\times 100$. Bar: 100 microns.

direction to the spinal cord axis results in a smaller dural sac hole and less CSF leakage less than when the bevel is pointed perpendicularly. However, their study cannot be compared with ours as it was undertaken using different needles although they were called the same. A detailed look at Franksson and Gordh's research ${ }^{7}$ reveals that the non-disposable bevelled needles named by them as "Quincke", are very different from the disposable "Quincke needles" used nowadays. The DAL caused by the "old Quincke needles" from the forties was of a different morphology. Those needles with no adequate bevel edge warranted larger lesions caused by a tearing action rather than a sectioning action whereas the use of "modern Quincke needles" results in a clean U shaped lesion.
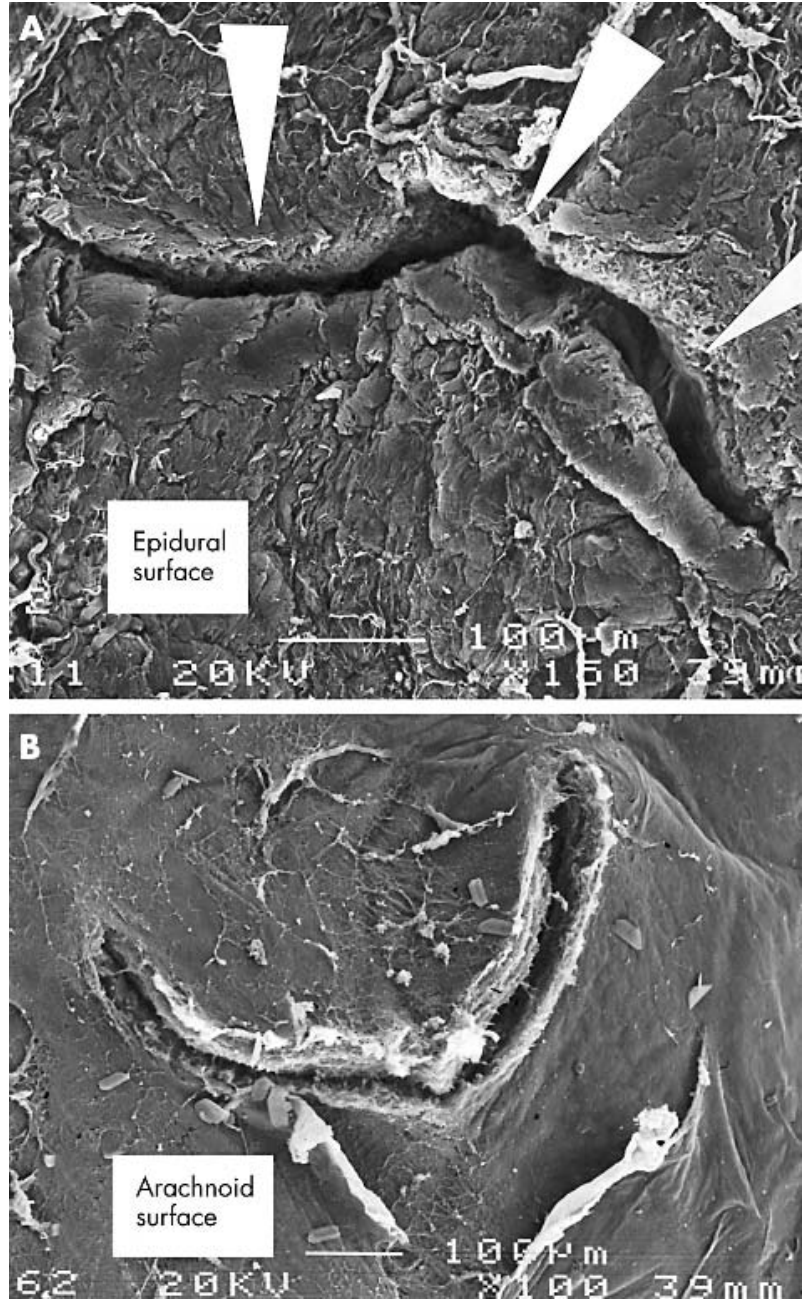

Figure 3 Dura-arachnoid lesion caused by a 22 gauge Quincke needle introduced with the bevel perpendicular to the axis of the spinal cord. (A) Epidural surface of the dural sac. Scanning electron microscopy $\times 150$. Bar: 100 microns. (B) Arachnoid surface of the dural sac. Scanning electron microscopy $\times 100$. Bar: 100 microns.

Old "Quincke" needles ended having the bevel completely modified as the result of the continuous use, the crashing into the vertebras, and the sterilisation techniques. Their bevels were blunt rather than cutting. We were able to prove all these features by analysing Quincke needles with scanning electron microscopy (SEM) and observing the bevel surface and its morphological details and by comparing the differences between Quincke needles made by different manufacturers. ${ }^{16}$

Other investigators have studied the DAL by light microscopy. ${ }^{17}{ }^{18}$ SEM allows us to assess the size and morphology of the dural and the arachnoid injury separately as well as verifying the lesion along its thickness and the dural laminas section. The dural sac is made on its $90 \%$ outer aspect of dural lamina and on its $10 \%$ inner side of neurothelial and arachnoid cells. Its innermost layer is made of arachnoid cells (arachnoid lamina) in close contact with the CSF. ${ }^{19-21}$

When puncturing the dural sac, Quincke needles cause less "tent effect" and overstretching of the fibres than "pencil point" needles because of their cutting action. The result is a clean, U shaped lesion or flap resembling the lid of an open can (hood mechanism). ${ }^{12}$ As the needle is withdrawn, the $U$ shaped flap tends to return to its original position with the help of the CSF pressure and the viscoelastic properties of the dura mater. 

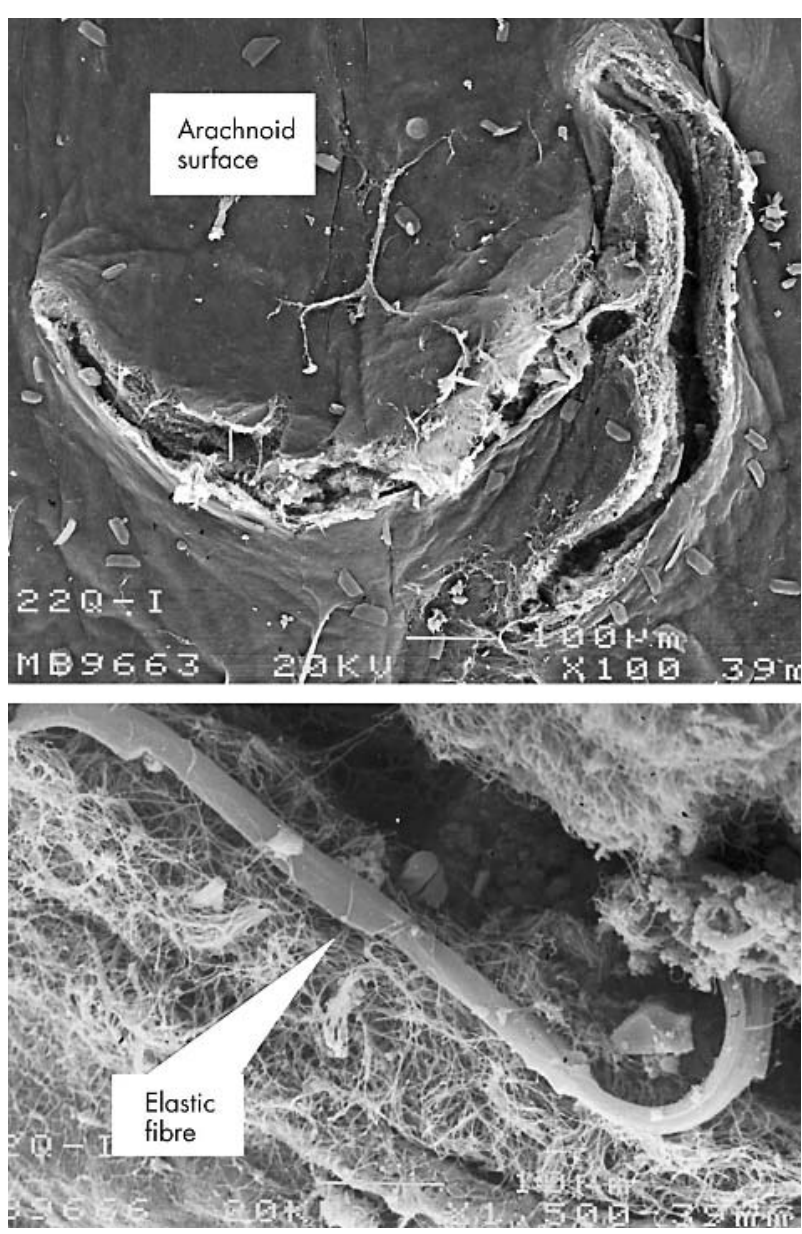

Figure 4 (A) Two dura-arachnoid lesions caused by a 22 gauge Quincke needle introduced with the bevel parallel and perpendicular to the axis of the spinal cord. Arachnoid surface of the dural sac. Scanning electron microscopy $\times 100$. Bar: 100 microns. (B) Detail of a dural lesion, a broken elastic fibre. Scanning electron microscopy $\times 1500$. Bar: 10 microns.

The development of PDPH is multifactorial. Some of the following alone or in combination may contribute to its appearance; dragging of skin cells ${ }^{22} 23$ and antiseptic solution with the needle tip, needle manipulation and contamination with surgical glove particles, ${ }^{24}$ number of failed puncture attempts, tip deformation when hitting bone, ${ }^{13-15}$ use of defective spinal needles, ${ }^{25}$ degree of previous cerebral vasodilatation, CSF pressure, CFS production-reabsorption, unexpected movement of the patient during the puncture, patient's position and degree of flexion of the vertebral spine, previous hydration status, abnormal distribution of craniospinal elasticity, ${ }^{26}$ substance $\mathrm{P}$ concentration, ${ }^{27}$ and operator skills.

Nevertheless, we must remain cautious when establishing a cause-effect relation in PDPH. In a meta-analysis looking at the relation between PDPH and different types of needle, ${ }^{28}$ of 46 articles 30 were rejected by the authors because of unsatisfactory study design or methodology.

Our study contains a number of limitations. Firstly, it is an "in vitro" study. The samples were not exposed to traction forces in a cephalic and caudal way on performing the punctures. However, in the clinical setting some patients are placed in the hyper flexion position leading to a greater DAL. ${ }^{29}$ Our conclusions can only be extrapolated to clinical practice if patients are placed on slight flexion of the vertebral spine and when aspiration of CSF comes from a clean, non-traumatic, and one single attempt puncture.

Secondly, we were unable to assess the role of CSF. In vivo, CSF pressure may affect the time the dural hole remains open. We did not measure pressure gradients across the duraarachnoid membrane.

We conclude that in isolated dural sac samples, puncturing the dura either perpendicular or parallel to the long axis of the dural sac does not affect the size of the lesion produced by the bevel. Further studies are warranted to confirm or disprove the present clinical practice recommendations concerning the insertion of needles for spinal puncture.

\section{ACKNOWLEDGEMENTS}

We are grateful to Mariá Concepción Villanueva (Pathology Department), Esperanza Sánchez-Brunete Palop (Transplant Unit Coordinator), Fernando Seller (Orthopaedic Department) at the Hospital de Móstoles (Madrid, Spain) for their invaluable contribution to this research study.

\section{Authors' affiliations}

M A Reina, A López, Department of Anaesthesiology and Critical Care, Hospital de Móstoles, Madrid, Spain

M A Reina, A López, V Badorrey, Department of Anaesthesiology, Hospital Madrid Montepríncipe, Madrid, Spain

J A De Andrés, Department of Anaesthesiology, Critical Care and Pain Therapy, Hospital General Universitario, Valencia, Spain

S Martín, Department of Anaesthesiology and Critical Care, Hospital Ramón y Cajal, Madrid, Spain

Funding: this study was supported by the Investigation Funds, Ministry of Health of Spain, Project 98/0628.

Competing interests: none declared.

\section{REFERENCES}

1 Bier A. Versuche uber Cocainisirung des Ruckenmarkes. Disch Z Chir 1899;51:361.

2 Mac Robert RG. The cause of lumbar puncture headache. JAMA 1918;70:1350-3.

3 Evans RW, Armon C, Frohman EM, et al. Assessment: prevention of postlumbar puncture headaches: report of the therapeutics and technology assessment subcommittee of the American Academy of Neurology. Neurology 2000;55:909-14.

4 Longo S. Postdural puncture headache: implications and complications. Curr Opin Anaesthesiol 1999; 12:271-5.

5 Davignon K, Dennehy K. Update on postdural puncture headache. Int Anesth Clin 2002;40:89-102.

6 Liu S, Mc Donald S. Current issues in spinal anesthesia. Anesthesiology 2001;94:888-906.

7 Mihic DN. Post spinal headache and relationship of needle bevel to longitudinal dural fibers. Reg Anesth 1985;10:76-81.

8 Flaatten $\mathrm{H}$, Thorsen T, Askeland B, et al. Puncture technique and postdural puncture headache. A randomized, double blind study comparing transverse and parallel puncture. Acta Anaesthesiol Scand 1998;42:1209-14.

9 Franksson C, Gordh T. Headache after spinal anesthesia and a technique for lessening its frequency. Acta Chir Scand 1946;94:443-5.

10 Reina MA, Dittmann M, López A, et al. New perspectives in the microscopic structure of human dura mater in the dorso lumbar region. Reg Anesth 1997;22:161-6.

11 Reina MA, López A, Dittmann M, et al. Structural analysis of the thickness of human dura mater with scanning electron microscopy. Rev Esp Anestesiol Reanim 1996;43:135-7.

12 Reina MA, De Andrés JA, López A. Subarachnoid and epidural anesthesia. In: Raj P, ed. Textbook of regional anesthesia. Philadelphia: WB Saunders, 2002:307-24.

13 Benham M. Spinal needle damage during routine clinical practice. Anaesthesia 1996;51:843-5.

14 Jokinen MJ, Pitkänen MT, Lehtonen E, et al. Deformed spinal needle tips and associated dural perforations examined by scanning electron microscopy. Acta Anaesthesiol Scand 1996;40:687-90.

15 Rosemberg PH, Pitkänen MT, Hakala PH, et al. Microscopic analysis of the tips of thin spinal needles after subarachnoid puncture. Reg Anesth 1996;21:35-40.

16 Reina MA, Gorra ME, López A. Presenza di cellule epiteliali nel canale midollare dopo anestesia spinale. Minerva Anestesiol 1998;64:489-97.

17 Celleno D, Capogna G, Constantino P, et al. An anatomic study of the effects of dural puncture with different spinal needles. Reg Anesth 1993; 18:218-21. 
18 Dittmann M, Schäfer HG, Ulrich J, et al. Anatomical re-evaluation of lumbar dura mater with regard to post spinal headache. Effect of dural puncture. Anaesthesia 1988;43:635-7.

19 Fink BR, Walker S. Orientation of fibers in human dorso lumbar dura mater in relation to lumbar puncture. Anesth Analg 1989;69:768-72.

20 Reina MA, López A, Dittmann M, et al. Analysis of the external and internal surface of human dura mater with scanning electron microscopy. Rev Esp Anestesiol Reanim 1996;43:130-4.

21 Reina MA, De León Casasola OA, López A, et al. The origin of the spinal subdural space. Ultra structure finding. Anesth Analg 2002;94:991-5.

22 Reina MA, López A, Dittmann M, et al. latrogenic spinal epidermoid tumors. A late complication of spinal puncture. Rev Esp Anestesiol Reanim 1996:43:142-6.

23 Reina MA, López A, Manzarbeitia F, et al. Skin fragments carried by spinal needles in cadavers. Rev Esp Anestesiol Reanim 1995;42:383-5.
24 Reina MA, López, Aguilar JL, et al. Electron microscopic analysis of particles from surgical gloves and their possible introduction into the epidural space during epidural anesthesia. Rev Esp Anestesiol Reanim 1999;46:60-6.

25 López A, Reina MA, Machés F, et al. Electron microscopy in quality control of equipment used in regional anesthesia. Tech Reg Anesth Pain Management 2002;6: 124-32.

26 Levine DN, Rapalino $O$. The pathophysiology of lumbar puncture headache. J Neurol Sci 2001;192:1-8.

27 Clark JW, Solomon GD, Senanayake PD, et al. Substance P concentration and history of headache in relation to postlumbar puncture headache: towards prevention. J Neurol Neurosurg Psychiatry 1996;60:681-3.

28 Halpern S, Preston R. Postdural puncture headache and spinal design: metaanalysis. Anesthesiology 1994;81:1376-83.

29 Zetlaoui PJ. Bevel orientation and postdural puncture headache. A new possible explanation? Acta Anaesthesiol Scand 1999;43:967-8.

\section{HISTORICAL NOTE}

\section{Primary lateral sclerosis and Pierre Marie}

$\mathrm{P}$

rimary lateral sclerosis (PLS) is an idiopathic nonfamilial neurodegenerative disorder of upper motor neurones. It presents as a slowly progressive pyramidal tract syndrome, sometimes with marked pseudobulbar symptoms.

The diagnosis is based on exclusion of other causes. Pringle and colleagues ${ }^{1}$ proposed diagnostic criteria in 1992 for PLS: adult onset; negative family history; duration of at least three years (to exclude motor neurone disease (ALS)); and normal blood, CSF, EMG, and MRI results. However, it remains an enigmatic, heterogeneous syndrome of uncertain nosology, for some clinically similar patients have varied patterns of symptom progression and physiology. ${ }^{2}$ MRS may show a reduction of $\mathrm{N}$-acetylaspartate/creatinine in the motor cortex. Modern technology can exclude other disorders with an accuracy of about $90 \%$. It is now frequently accepted ${ }^{3-5}$ as a benign ALS variant, yet some disagree. ${ }^{2}$

Often confused with ALS, its existence as an entity has been debated since the time of Pierre Marie. In his classic book, Lectures on diseases of the spinal cord, ${ }^{6}$ Pierre Marie observed:

"In 1875, Erb7 and a few months later Charcot described an affection with pronounced 'spasmodic paresis' [In the nineteenth century the word spasmodic was often used to mean spastic, not episodic.] in the extremities, without loss of sensation. Erb believe this was due to primary degeneration of the lateral columns of the cord. Charcot was of the same opinion. This idea as to the nature of spasmodic spinal paralysis (name given by Erb) or spasmodic tabes dorsalis (name given by Charcot), thus at once gave it the right of being included in nervous pathology, but owing to a singular misfortune the autopsies of adult patients in whom the diagnosis...had been made, there was found either disseminated sclerosis or transverse, or focal myelitis, or perhaps amyotrophic lateral sclerosis; not a single case in fact occurred in which primary degeneration of the pyramidal tract existed...thus during the last few years the diagnosis of spasmodic tabes dorsalis has scarcely ever been made." p84

Marie went on to say: "The diagnosis should be excluded from a 'nosological catalogue' with the exception of congenital spastic rigidity of the limbs", which he recognised as Little's disease.

It remains mandatory to exclude: compressive lesions at the foramen magnum and cervical cord, MS, Chiari malformation, and human immunodeficiency virus or human T-lymphotrophic virus type I. In PLS and in ALS morphometry shows small pyramidal cells in the precentral gyrus; and in PLS, quantitative histopathology shows the neuronal degeneration confined to the corticospinal system, without involvement of lower motor neurones. ${ }^{1}$ Its place in neurological taxonomy is still unclear.

J M S Pearce

304 Beverley Road, Analby, Hull HU10 7BG, UK; jmspearce@freenet.co.uk

\section{References}

1 Hudson AJ, Kiernan JA, Munoz DG, et al. Clinicopathological features of primary lateral sclerosis are different from amyotrophic lateral sclerosis. Brain Res Bull 1993:30:359-64

2 Zhai P, Pagan F, Statland J, et al. Primary lateral sclerosis: a heterogeneous disorder composed of different subtypes? Neurol 2003;22:1258-65.

3 Marshall J. Spastic paraplegia of middle age: A clinicopathological study. Lancet 1955; 1:643-6.

4 Kuipers-Upmeijer J, de Jager AE, Hew JM, et al. Primary lateral sclerosis: clinical, neurophysiological, and magnetic resonance findings. J Neurol Neurosurg Psychiatry 2001;71:15-20.

5 Younger DS, Chou S, Hays AP, et al. Primary lateral sclerosis. A clinical diagnosis reemerges. Arch Neurol 1988;45:1304-7.

6 Marie P. Leçons sur les maladies de la moelle. Paris, Masson 1892. English translation Montagu Lubbock. London: The New Sydenham Society, Vol CLII, 1895.

7 Erb WH. Ueber einen wenig bekannten spinalen symptomencomplex. Berliner Klinische Wochenschrift 1875;12:357-9. 